\title{
Cultural Planning and Community Sustainability: The Case of the Cultural Facilities Plan of Catalonia (PECCAT 2010-20)
}

\author{
Santi Martínez i llla \\ Joaquim Rius i Ulldemolins \\ Generalitat de Catalunya, Spain
}

\begin{abstract}
The government of Catalonia has developed a planning framework that seeks to establish the provision of cultural facilities throughout the country. The Cultural Facilities Plan of Catalonia (PECCAT) is based on an analysis of historical gaps and establishes a minimum spatial scheme. The plan responds to problems associated with the absence of a former similar instrument, which has led to an inconsistent and inappropriate cultural infrastructure that fails to fulfill its fundamental mission of securing the cultural rights of the population.

The paper sets forth the aims of this policy and describes the objectives and basic characteristics of the plan and the expected outcomes. With the plan, the government of Catalonia seeks to rebalance the infrastructure within the territory and to ensure universal access to basic cultural services, while avoiding a logic of standardization and taking local communities into account. With the development of local plans in the municipalities, local governments encourage community participation processes to adapt and decide on priorities for action based on needs assessments and cultural opportunities for local sustainable development. The local plans focus on local cultural strengths, take advantage of opportunities, and aim to realize the cultural dynamics of a place through establishing an infrastructure that can best respond to the needs and cultural demands of the local communities, taking into account economic, social, and environmental sustainability.
\end{abstract}

Keywords: cultural planning, local participation, sustainability, governance, Catalonia

Résumé : Le gouvernement de la Catalogne a mis au point un cadre de planification qui a pour objectif de développer plusieurs équipements culturels dans tout le pays. Le Plan équipements culturels de la Catalogne (PECCAT) est basé sur une analyse des lacunes historiques et établit un minimum schéma spatial d'organisation et de développement culturel. Le plan répond aux problèmes liés à l'absence d'un outil antérieur similaire, ce qui a conduit à une infrastructure culturelle contradictoire et inappropriée qui ne répondit pas à sa mission fondamentale, soit d'assurer les droits culturels de la population.

Santi Martínez i Illa is Head of the Facilities Planning Service in the Department of Culture of the Government of Catalonia, Spain. E-mail: samartinez@gencat.cat. Joaquim Rius i Ulldemolins is Researcher of the Facilities Planning Service in the Department of Culture of the Government of Catalonia and Associate Professor of cultural policy in the Open University of Catalonia (UOC), Spain. E-mail:jriusu@ uoc.edu.

Culture and Local Governance / Culture et gouvernance locale, vol. 3, no. 1-2, 2011. ISSN 1911-7469

(C) Centre on Governance, University of Ottawa, 55 Laurier Avenue East, Ottawa, Ontario, Canada K1N 6N5 
Le document expose les objectifs de cette politique et décrit les objectifs et les caractéristiques de base du plan et les résultats attendus. Avec le plan, le gouvernement de la Catalogne cherche à rééquilibrer les infrastructures sur le territoire et d'assurer l'accès universel aux services culturels, tout en évitant une logique de standardisation et de prendre en compte les communautés locales. Avec le développement de plans dans les municipalités, les gouvernements locaux encouragent les processus de participation des citoyens pour adapter et décider des priorités d'action, sur la base des évaluations des besoins et des opportunités culturelles pour le développement local durable. Les plans locaux se concentrent sur des atouts culturels ancrés dans le territoire local, pour tirer parti des opportunités, et essayer d'aider la dynamique culturelle d'un lieu par la création d'une infrastructure apte à répondre au mieux aux besoins et exigences culturelles des communautés locales, en tenant compte des aspects économiques, sociaux, et la durabilité de l'environnement.

Mots clé: planification culturelle, équipements culturels, participation locale, durabilité, gouvernance, Catalogne

\section{Introduction}

The Cultural Facilities Plan of Catalonia (PECCAT 2010-20), driven by the autonomous government of Catalonia ${ }^{1}$, has been formulated to promote the construction and rehabilitation of infrastructure to complete a system of public cultural facilities in the municipalities of Catalonia. It aims to boost equal opportunities to access culture, support creativity, and contribute to social cohesion and the sustainability of local communities. The plan is structured as a master plan for ordering the system of public cultural resources, introducing basic rationalization criteria in determining and distributing funds. Nowadays, most facilities belong to the municipalities; therefore, the plan has been formulated within a framework of governance, seeking consensus with local governments in Catalonia.

The culture department of the Catalan government has launched a support program for municipalities in the country to develop their own local cultural facilities plans, which will mean a substantial advance in the spread of the 'culture of cultural planning' in a global sense in this country. In this way, the plan aims to develop local plans that facilitate a better fit between the guidelines and criteria at the national level and local dynamics. This resource invites local governments to construct facilities that are in line with their cultural reality, strategic vision, and creative potential. These local plans involve local participation processes that are open to local cultural actors and incorporate the need to establish sustainability criteria in their further development, both with regard to the design of the facility and its subsequent operation and maintenance.

\footnotetext{
${ }^{1}$ The Generalitat of Catalunya, the Catalan regional government within the framework of the decentralized Spanish government, is endowed with wide almost-federal competences and has had exclusive competences in culture and in territorial planning since 1979. However, the local governments have always been the main instigators, investors, and managers of the cultural facilities in Catalonia.
} 


\section{The effect of cultural land planning}

The need for a global cultural facilities scheme has been a historical demand of the cultural sector in Catalonia since the restoration of democracy and autonomy in the late 1970s. The government institutions rooted in democracy began their tasks in the face of a general lack of public cultural facilities and a severe lack of funds, as well as a legislative framework that facilitated competition among the different levels of government. Added to this was a structural determinant: the high fragmentation and heterogeneity of the municipal map of Catalonia which added even more complexity to the situation. ${ }^{2}$ A planning tool of this kind was conceived as an obvious necessity, given the situation, but in spite of all the evidence, the establishment of a global plan was not adopted as a priority by former Catalan governments.

During these years, the huge deficit inherited from the dictatorial period was addressed mainly through the initiative of local governments that took the lead in public investment in culture. But this local action occurred without a management scheme or a defined and stable funding framework. Only some sectors - mainly the public libraries and, to a lesser extent, the archives adopted a global scheme with corresponding finance funds. ${ }^{3}$ As a consequence of these dynamics, the map of cultural resources lacks consistency. It has been formed as a result of local initiatives, the result of isolated wills and short-term opportunities, which have failed to address all outstanding deficits.

In recent years, the Catalan economy has evolved in line with the Spanish one, benefiting from a growth cycle based on an unsustainable development model in which the construction sector was considered almost the sole factor in economic growth. This growth provided the coffers of the municipalities with funding derived from urban expansion, but this has suddenly stopped with the outbreak of the financial crisis. In this context, many municipalities have built cultural facilities with these resources, but often at an unmanageable cost to the municipality in the mid- and longterm, as revenues are now in freefall due to the economic crisis. Some of these cultural facilities were built more as a result of opportunities arising from the voluntarism of local cultural actors and the context of the previous economic boom rather than as a response to the cultural needs or demands of the local communities. Therefore, the lack of planning directives and standards has been one of the factors that have led to infrastructure of dubious feasibility from an economic point of view and, above all, from a social and cultural perspective.

At this point, important questions arise: In the first decade of the twenty-first century, is a plan of this nature still the best tool to complete and bring coherence to the system of public cultural facilities? Could it be an overly rigid tool? Is a framework like this much more appropriate for an environment of economic growth and public budget stability than for the current economical crisis and budgetary reduction scenarios? Most likely, these are largely rhetorical questions: it cannot be claimed that we are in the golden age of planning as it is understood in a conventional sense. Evans \& Foord (2008), in their analysis of the evolution of cultural planning in the United Kingdom, conclude that traditional planning methodology is now inadequate. In fact, the emergence of

\footnotetext{
${ }^{2}$ Catalonia has 947 municipalities, of which more than 500 have fewer than 1000 inhabitants and a large number have fewer than 100 .

${ }^{3}$ Law 4/1993, of 18 March, of the libraries system of Catalonia; Law 10/2001 of archives and documents.
} 
territorial strategic planning and its generalization from the 1980s and 1990s has been interpreted as a more appropriate framework than conventional planning: "A formula that allows the design of future scenarios that are flexible enough to adapt to a reality that is changing at high speed" (Ganau \& Mallarach 2003, p. 8)

The adoption of a master scheme for the delivery of public services based on a strategic regional planning framework was proposed in France in the context of a 1999 law on regional planning guidance and sustainable development. This law established the so-called 'collective services schemes' projected as strategic planning devices which were intended to reconcile the main governmental action priorities with local needs over a 20-year period. The plans were designed to tackle three basic objectives: to promote the dynamism of the territories, to protect and optimize the functioning of public services, and to integrate sustainable development requirements. In the field of culture, the scheme proposed a shift towards "new spaces, new practices and new territories," establishing a framework of general objectives, and made the regional governments responsible for the realization of their plans (DATAR 2001, p. 2). In the United Kingdom, the adoption of a similar pattern occurred in the context of an overall strategy for sustainable infrastructure planning (ODPM 2005).

The appeal to the relevance and validity of cultural planning and its relationship with the development of creative territories (Mercer 2006) has been articulated recently in the Anglo-Saxon world both in the United Kingdom - "the growing demand for a structured process for planning of cultural facilities has emanated from both the government level, local and regional, and cultural sector" (Evans \& Foord 2008, p. 65) - and in North America, specifically in Canada by the Creative City Network of Canada, which focused on the local level (Russo \& Butler 2007; Duxbury 2008).

The cultural facilities plan in Catalonia did not fully adopt an alternative framework and it retains, in part, the classic scheme based on the incremental logic of delivery of public services. Therefore, the development of local plans requires adoption of such an alternative framework aimed at strategic planning of sustainable communities as proposed by Evans \& Foord (2008).

The planners assumed that it was imperative to avoid sterile regulations and standardization logic, which would have the opposite effect to the objectives sought. However, the absence of minimum guidelines has led to the current situation, with the proliferation of inconsistent locations and the setting up of venues with various deficiencies and functional inadequacies. In this regard, it is noteworthy that one of the premises of this kind of planning exercise is the efficient use of public resources through objective territorial allocation of these resources.

This same vision has also been adopted by other public government departments charged with the delivery of public services in Catalonia, such as sports, and public housing, which have recently drawn up global planning schemes. ${ }^{4}$

\footnotetext{
${ }^{4}$ This planning structure derives from the Law of Territorial Policy of 1983, but was not fully deployed until very recently.
} 


\section{The basic scheme of PECCAT ${ }^{5}$}

Broadly, the plan identifies several types of public cultural facilities intended to provide basic cultural services to citizens, facilitate access to culture, and promote cultural participation, social cohesion, creativity, and sustainability. In this sense, if we consider the analysis model proposed by Dang \& Duxbury (2007), the plan would have a preferred orientation towards people (buildingcentred vs. people-centred) and towards decentralization (clustering vs. decentralization).

As noted previously, the plan is based on various factors:

- The absence of a previous management framework that has resulted in a distribution of public facilities characterized by global deficits and geographic imbalances. It may be recalled that the public offer of cultural services in Catalonia started considerably later than in our European neighbours, only dating back to the development of democratic local councils in 1979.

- Recent demographic trends that have led to strong growth in the past decade, mainly related to migration, with a related increase in heterogeneity and diversity of the population in social and cultural terms. These factors have resulted in a marked increase in demand for public cultural services to cater to the needs of the settlement and integration of this new more diverse and complex citizenship. ${ }^{6}$

- The strong impact of the development of digital media and ICT on conventional forms of access to culture, which makes it necessary to rethink cultural facilities, their orientation and, above all, their aims and functions.

- To carry out this mission successfully, theoretical service delivery needs were identified and compulsory service standards were set up for each kind of cultural facility. The definition of requirements was based on theoretical analysis of the current situation in each of the publicly subsidized cultural sectors. This definition has encouraged the participation of professionals and experts in the respective cultural sectors, most with professional experience in local governments, to establish a framework of consensus with local operators since they are fundamental in developing the plan.

Basic cultural facilities were defined as those in the cultural sectors that have a strong tradition of public intervention in our country, in particular libraries, archives, museums and heritage, music and performance facilities, cultural centres, and visual arts venues. Another group has been labelled as 'new generation spaces' to accommodate unconventional and innovative proposals.

Basic needs have been established from a combination of demographic and spatial parameters with various correction factors in the theoretical location of infrastructure. Once basic needs are stated they are contrasted with existing resources in order to map deficits. This mapping is made

\footnotetext{
${ }^{5}$ All documents of the plan can be found at www.gencat.cat/cultura.

${ }^{6}$ The population of Catalonia has increased more than $15 \%$ in less than 10 years, a growth based almost solely on migration: residents of foreign origin increased from a little more than $1 \%$ to nearly $20 \%$ of the population during this period. With this evolution, Catalonia has become one of the most diverse and complex societies of Europe, with 937 of its 947 municipalities having resident populations of foreign origin.
} 
with the consent of local authorities. The plan starts from this map of deficits and establishes a program with a timetable and priorities for action.

The plan does not propose direct investments because it acknowledges the fundamental role of local government in providing basic cultural services in Catalonia. It is not intended to alter the current scenario with the establishment of a new network of basic cultural facilities depending on the Catalan government, but to support local governments in their projects. Thus, it is intended that these plans contribute to building a public network of cultural resources promoted both by the Catalan government and local administrations. ${ }^{7}$

The plan includes a minimum of 395 new facilities or comprehensive refurbishment of old ones, which will incorporate an undetermined number of proposals that may emanate from local plans. To attain this goal, the culture department must provide local governments with regular subsidies covering up to $50 \%$ of the investment. The local governments have to carry out the venue projects in their cultural context and establish an operating plan in order to guarantee both sociocultural aims and operational sustainability. ${ }^{8}$ The first call for subsidies was planned for the year 2010.

The success of the project will be measured, first, in terms of the increase of the offer of cultural facilities. In this sense, the plan will include a set of input and output performance indicators. These kinds of indicators will be used to measure the evolution of cultural practices linked to participation. The indicators will be operative as soon as the planned facilities open their doors. The ultimate goals of the plan will be measured in terms of outcomes related to impacts expected from promoting the country's cultural development, creativity, social cohesion, or territorial balance. The next step is the development of an information system in order to measure the global performance of the facilities. A review of the performances carried out within the framework of the Plan will be carried out annually and a global evaluation will be carried out in 2015.

The expected environmental impact of the Plan has also been evaluated by the Department of Environment of the Government of Catalonia. As a result of this evaluation, targets and recommendations have been included. These targets focus on minimizing water and energy consumption and minimizing the amount of travel generated by the facilities. In addition, it has been agreed that a joint follow-up will be carried out annually by the Departments of Culture and Environment in order to evaluate the degree of environmental sustainability of the cultural facilities according to ten previously established indicators.

However, the so-called 'extra-cultural' outcomes and other externalities that will no doubt fuel their development should not be underestimated. Regarding economic impact, an initial study estimated that the multiplier effect of expected investments may exceed $72 \%$, so with the forecast initial investment of $€ 1.200$ million, the final economic impact could exceed $€ 2.000$ million (Generalitat de Catalunya 2010, pp. 143-146).

\footnotetext{
${ }^{7}$ In February 2009 the decree that regulates the creation of the 'Network of public stage and music facilities of Catalonia' was approved. The creation of a new network for centres of art and contemporary creation is now almost completed.

${ }^{8}$ The procedure is similar to the Canada Cultural Spaces Fund (formerly Cultural Spaces Canada) program of the Department of Canadian Heritage but addressed mainly to local governments.
} 


\section{Sustainable cultural facilities for sustainable communities}

The identification of needs consists of two basic elements: first, the definition of services in terms of building design, functions, and aims of the facilities and, second, their geographical distribution. In both elements, the sustainability paradigm emerges as a decisive factor.

In relation to the conception and design of resources, the plan includes environmental requirements and criteria for building, operation, and management, and also considers cultural facilities themselves as a means of conveying values of environmental sustainability. With regard to territorial distribution, it establishes the priority that citizens should not have to travel far from their place of residence to access cultural content and events, community practices, and artistic experiences. The cultural facilities are seen as fundamental factors for communities in promoting their culture, creativity, cohesion, and sustainability.

From a strictly operational point of view, the plan incorporates an environmental report that highlights the following items:

- Prioritizing the rehabilitation of existing buildings versus building new resources. PECCAT is considering recognizing non-profit organizations with public value orientations as part of the public network of facilities. ${ }^{9}$ Agreements on the use and management of facilities belonging to these organizations (usually old theatres) address a comprehensive need to maintain the local architectural heritage and historical memory, while fostering those social organizations and minimizing the consumption of land, building materials, and energy.

- The refurbishment of buildings is not considered an absolute value but is relative to the future use of the equipment and its sustainability. Therefore, the building should be compatible with the uses set out in the operational plan and overly large venues should be avoided. In this regard, the plan aims to prevent unplanned proliferation of the reuse of old industrial buildings (so-called 'cultural factories') when their sustainability as a project is uncertain. The decision on whether or not the facilities are to be reused will be placed in the context of local plans.

- A commitment to sustainable building, giving priority to those with energy efficiency. ${ }^{10}$ Environmental compliance criteria and eco-efficiency in buildings beyond the current legal criteria are also valued. ${ }^{11}$ In other words, the establishment of energy-efficient lighting

\footnotetext{
${ }^{9}$ In Catalonia, more than a hundred social centres were constituted in the second half of the nineteenth century and the first half of the twentieth century. They were promoted by civil society to make up for the lack of public cultural and educational policies. Many of them were the initiative of popular sectors inspired by the ideals of the Enlightenment and libertarian ideas. Nowadays, many of them continue to exert a remarkable social and cultural dynamism but in other cases, due to organizational weaknesses, they have difficulty affording to maintain and refurbish heritage buildings. Because of this problem, in some cases it has been possible to reach agreements between these entities and local governments to share the upkeep and management of the buildings in exchange for financial assistance, which provides a modern cultural resource to the community (Roselló \& Rius 2010).

${ }^{10}$ It is related to achieving more than level C, as established by the 2002/91/EC Directive on energy certification of buildings.

${ }^{11}$ Decree 21/2006 of the Catalan government.
} 
systems, natural ventilation, thermal insulation, rainwater reuse, renewable energy use for air conditioning, or utilization of products obtained by recycling waste as construction materials are considered as part of the criteria for granting funds for the construction of these facilities.

- Minimization of travel generated by the geographical accessibility of cultural facilities. Although attendance at arts performances and events in Catalonia represents only $4.6 \%$ of trips for leisure purposes on a working day and $13.7 \%$ on weekends (IERMB 2006), the plan gives priority to locating cultural facilities in areas of high urban density, thereby facilitating access by foot, public transportation, or cycling (making it necessary to install cycle parking facilities).

- The introduction of criteria for 'green procurement' or environmental standards in procurement of goods and services for the facilities.

\section{Attention to the uniqueness and creative potential of the territories}

Since the beginning of the planning process, the first and fundamental concern shown by cultural agents consulted and involved was the possibility that an overly rigid scheme would eventually be implanted that could damage the skills and creative abilities of a local place or territory. These concerns were both with regard to the location criteria and to the standards definition (Martinez \& Picas 2010). This was the main fear expressed by people involved in cultural management in municipalities that, for one reason or other, had managed to consolidate local cultural projects that made them landmark locations. Cities with projects recognized for their emphasis on creativity and risk were rewarded with high levels of public investment. Managers and policymakers in these cities feared that with the establishment of a global scheme, their cultural ecosystem would be constrained to predetermined categories, which would remain unchanged indefinitely and would 'dumb down' the profile of all municipalities. This situation would lead to the development of an undifferentiated space, formed by logical default units and hierarchical dynamics. This would hinder local desires and initiatives aimed to convert indeterminate places to unique places.

In response to these legitimate concerns, it must be emphasized that the fundamental aim of the plan is to establish a spatial planning framework to provide a dose of rationality where lack of discretion or whim could jeopardize the public investment effort. In no way is the plan intended to prevent the development of creativity and talent wherever it occurs. In this respect the following should be pointed out:

- The mapping of specific needs and deficits does not imply setting up new facilities automatically and indiscriminately: the initiative always belongs to local governments. The plan may not be used to create facilities that are empty of cultural content and activity.

- The recommendations in the plan establish the need to orient the new facilities toward contemporary social and cultural transformations, and set out guidelines to provide suitable facilities to meet the opportunities and challenges that digitization and the emergence of new media formats bring to cultural processes and current practices.

- The plan sets standards for basic cultural facilities, but does not close the doors to innovation and recognizes new generation facilities, where projects that transcend basic 
formats can be accommodated, such as 'creative factories,' media culture, media labs, and so forth.

- The plan opens the door to the design of compact spaces that encourage versatility and a variety of uses.

- The plan does not determine the form of management of the public cultural facilities. Local governments make that decision and can opt for formulas of management open to the participation of third sector organizations.

The plan provides for the convenience of creating clusters of cultural facilities (e.g., library, cultural centre, theatre, auditorium) to benefit from common services such as reception, administration, monitoring, and so forth, resulting in savings in construction and staff necessary for management. In order to articulate these and other developments that may arise from local initiative, the global plan incorporates, as mentioned previously, the local plans as a parallel and almost compulsory planning tool, and the culture department regularly has to allocate subsidies to local governments to develop such plans.

\section{The impulse for local planning: Local plans}

With this tool, local governments are invited to build upon their own sense of a place in line with their cultural realities, strategic vision, and creative potential. They must focus on the local reality and incorporate demographic variables, geographical distribution, seasonal population, and territory variables, both intra-municipal (districts, boroughs) and inter-municipal (structures and cooperation networks). There is also a need to look at the intersections with other sectors at the local level, such as education, sports, and social services. It is at the local level where the size and scope of sectors' interactions and the versatility of infrastructure, activities, and action programs can be specified.

With the development of these plans, a satisfactory fit between the spatial pattern defined at the global country level and the specific focus on local places can be achieved. This process allows for the introduction of elements of variable geometry in the localization of facilities beyond the administrative structure, and provides rational governance to the process through the incorporation of specific strategic planning mechanisms. The methodology of local plans makes it necessary to involve local residents in the decision-making process so that municipalities can propose their local planning scheme. This participation may be different and adapted to the social and associative structure and to the cultural sector in each place but, in general, it involves convening sessions open to the participation of the local cultural sector and residents.

\section{Local cultural planning and sustainability}

As mentioned previously, the methodology of preparing local plans also includes a specific section on environmental analysis and sustainability. This resource is to ensure that sustainability measures are incorporated in a systematic way into local cultural planning, a logic that is specific in areas such as the following:

- Local plans necessarily include an operational development project for each new facility proposed. Therefore, the building requirements are defined according to the purposes and uses of the facility, which makes the calculation of building and management costs much 
more accurate. Later, they also include a business operation plan for each new facility, including maintenance costs and the cost of the professional management team. These two elements help to define the size of the facilities in relation to real needs and economic resources available to build and maintain medium- and long-term facilities - two elements that can contribute to a more sustainable development.

- Local plans should identify facilities belonging to private and to third-sector owners that can be incorporated into the public cultural network, especially those that already have a cultural use (cultural centres, cinemas, theatres, etc.). Subject to agreement with their owners, they can be refurbished and developed for new cultural uses, thus reducing the consumption of land, materials, and energy with respect to the construction of new buildings.

- Local plans have to consider the application of environmental sustainability measures (e.g., building energy efficiency, use of renewable energy sources, water re-utilization, etc.) consistent with the provisions of the PECCAT.

- An important part of the local plan is the choice of the location of the facilities. Since the local plan plays a very important part in choosing between alternative locations, it will have an important role in introducing the criteria of accessibility by foot, bicycle, or public transportation in decision-making.

- Finally, the plan includes the recommendation to adopt environmental energy management systems to ensure that measures for environmental sustainability develop on a permanent basis. Environmental sustainability indicators (travel generated, energy, water, renewable energy utilization, among others) to monitor the correct implementation of environmental measures are also included.

\section{Conclusions}

Cultural planning is a territorial resource and a necessary force when applied following a methodological approach in line with the current context, a context that requires flexibility, attention to the mechanisms of governance, and guidance with regard to sustainability scenarios and goals. On these grounds, the plan for cultural facilities in Catalonia (PECCAT) sets out a minimum layout on a general scale. It establishes basic rules of the game, but the end result is modulated, made concrete, and adapted by particular local perspectives, with suitable responses to local circumstances reflecting its cultural and creative potential.

The plan arises from the need to cover inadequacies due to uneven development resulting from previous cultural policies. Based on standards of public delivery, it serves to correct inherited regional imbalances and establishes technical and environmental requirements to avoid functional problems and promote the sustainability of facilities.

The territorial plan incorporates as parallel tools the local plans, which incorporate an updated and detailed diagnosis of needs based on local cultural dynamics and the status of existing cultural facilities, both public and third sector. This allows local authorities to take advantage of opportunities to reform or rethink the use of older facilities and to adapt them to current cultural 
needs. But decisions must emerge not only from social and political consensus but must also demonstrate that projects are technically and environmentally appropriate, socially and economically viable, and therefore sustainable at the local level.

The participation of cultural actors allows for the development of projects tailored to local cultural strengths and real needs. The plan articulates a process of decision-making that both local and regional governments should take into account. This moves away from top-down classical planning without regard to local wishes that runs the risk of allocating resources inefficiently. It also avoids making decisions based solely on local government's wishes, which are sometimes the result of a situation or opportunity that is not based on criteria of need or a long-term view. The local plan functions as an essential tool to ensure the sustainability of long-term facilities.

Territorial and local planning are linked in a way that establishes a governance mechanism between the government of Catalonia, municipalities, and cultural actors in the municipalities. Ultimately, the cultural facilities are not just buildings but true catalysts for local creativity and for territorial and social cohesion and, ultimately, an axis of sustainable communities.

\section{References}

Ajuntament de Barcelona. (2006). Pla estratègic de cultura de Barcelona. Barcelona: ICUB. www.bcn.cat/plaestrategicdecultura

Dang, S.R. \& Duxbury, N. (2007). Planning for cultural infrastructure on a municipal or regional scale: Key frameworks and issues from the literature. Working Paper no. 5. Vancouver: Centre of Expertise on Culture and Communities, Simon Fraser University. www.cultureandcommunities.ca/downloads/WP5Planning-Cultural-Infrastructure.pdf

Generalitat de Catalunya. (2010). Pla d'equipaments culturals de Catalunya 2010-2020. Barcelona: Generalitat de Catalunya Departament de Cultura. www20.gencat.cat/docs/CulturaDepartament/ SGEC/Documents/Arxiu/PecCat_versio\%20definitiva.pdf

Institut d'Estudis Regionals i Metropolitans de Barcelona. (2006). Bellaterra: Enquesta Mobilitat Quotidiana.

DATAR. (2001). Schéma de services collectives culturelles. Paris: Ministre de la Culture et la Comunication. www.diact.gouv.fr/fr_1/archives_799/planification_spatiale_214/schemas_services_collectifs_215/ssc _culturels_806.html

Duxbury, N. (ed.). (2008). Under construction: The state of cultural infrastructure in Canada. Vancouver: Centre of Expertise on Culture and Communities, Simon Fraser University. www.cultureandcommunities.ca/cecc/resources/publications.html

Evans, G. \& Foord, J. (2008). Cultural mapping and sustainable communities: Planning for the arts revisited. Cultural Trends, 17(2): 65-96.

Ganau, J. \& Mallarach, J. (2003). La planificació estratègica territorial a Catalunya, Barcelona: Generalitat de Catalunya.

Martínez, S. \& Picas, O. (2010). Planificación cultural y territorios creativos, Ciudades creativas, Vol. 2. Barcelona: Fundación Kreanta.

Mercer, C. (2006). Cultural planning for urban development and creative cities. Paper presented at the conference 'Culture and Creativity as a Driving Force in Local and Regional Redevelopment,' Helsinborg, Sweden. www.culturalplanning-oresund.net/PDF_activities/maj06/Shanghai_cultural_ planning_paper.pdf

Office of the Deputy Prime Minister (ODPM). (2005), Sustainable communities: People, places and prosperity. London: ODPM. 
Roselló, D. \& Rius, J. (2010). La cooperació entre ateneus I ens locals per una cultura del segle XXI. Barcelona: Generalitat de Catalunya.

Russo, A. \& Butler, D. (2007). Cultural planning toolkit. Vancouver: City Creative Network of Canada. www.creativecity.ca/english/online-resources-mainmenu-144/ccnc-publications-mainmenu-169/ toolkits 